\title{
Bid Farewell to Time
}

\section{Study on the Design and Development of Hospices}

\author{
Junshu Guo \\ School of Architecture and Art \\ North China University of Technology \\ Beijing, China
}

\begin{abstract}
With the continuous advancement of medical technology, the world's population is continuously growing. People are having wider and deeper understanding of diseases. The incidence of diseases such as cancer is also increasing. Patients and their families have a growing demand for the hospice care institutions or facilities. In this article, the author first explored the history of hospices, then studied the design of several exemplary hospices at home and abroad, finally discussed the design elements of hospices, and put forward some views on the development and design of hospices in China.
\end{abstract}

Keywords—hospice care; hospices; humanity; space design

\section{INTRODUCTION}

The problems that life faces in the world are nothing but birth, being old, illness, and death. To sum up, they are: a birth with high quality, a good life, the great medical experience and hospice care. But often the public only pays attention to the first three aspects listed above, and greatly ignores the hospice care.

Everyone will experience the end of life. In order to allow people to face the next death with dignity, whether it is death from disease or natural death, it is necessary to provide them with appropriate psychological care and livable space, and to fully meet the physical and psychological needs of the dying person from the aspects of clothing, food, housing and transportation. Hospices can meet this demand, so they are particularly important.

\section{RESEARCH ON THE BACKGROUND OF HOSPICES}

\section{A. Hospice}

Hospice care refers not only to the care and nursing for the elderly, but also to care and nursing for patients with chronic serious diseases.

1) Definition of hospice: The hospice campaign began at the ST. Christophers' Hospice in the United Kingdom. In the 1950s, the British nurse Cicell Saunders witnessed many critically ill patients in agony before they died in the hospital that she had worked for many years. So she was determined to change this situation. In 1967, Sanders founded ST. Christophers' Hospice, a world-famous hospice care institution, to make seriously ill patients be well looked after in the final stages of their lives. People in later ages said that Saunders' behavior "ignited the lighthouse of the hospice movement". Since then, the hospice care movement has begun its globalization. Many countries have successively carried out hospice related activities. In the late 1970 s, the definition of hospice care was introduced into the United States, and in the late 1980s it was introduced into China.

2) The goal of hospice care: The main goal of hospice care is to improve the patient's quality of life from aspects of psychology, life, etc; eliminate or reduce the physiological symptoms of the patient as far as possible using various means besides normal medical methods; solve patients' psychological problems that arise in the process of illness and relieve their mental stress; help them face death with a more positive attitude and in a relatively calm state. At the same time, hospice care also takes into account the relief of the patient's family's burden and their mental pressure.

Unlike euthanasia, which aims to relieve patients of pain as early as possible, hospice care neither promotes nor delays the patient's death. The main tasks of hospice care include symptomatic treatment, family care, relieving or controlling pain, and alleviating or eliminating the psychological burden and negative emotions of patients and their families. This imposes high requirements on the professional skills of hospice care practitioners, so there are often staffs with various professions participating in hospice care and working together.

\section{B. Hospice Medical Buildings}

1) Definition of medical building: Medical building refers to the building in which doctors can carry out medical activities to protect people's health or help people restore or maintain their physical functions, such as general hospitals, specialist hospitals, outpatient departments, nursing homes and so on.

In the history of Chinese architecture, the existence of medical buildings is still very short. Medical building is one of the most complex buildings in civil buildings. This characteristic also determines that the development of medical buildings is more difficult than that of other civil buildings. China's medical buildings (institutions) appeared in the 11th century, but it was until in the 1920s when a large number of foreigners came to China and spread churches and religions extensively that hospitals such as Boji Hospital in Guangzhou, 
Daoji Hospital and Union Hospital in Beijing were established. These hospitals were all established by foreigners in the name of the church.

After the 1920s, lots of Chinese students who were studying abroad began to return to China. Among this batch of students, there was the first generation of real architects in China. The Nanjing Central Hospital designed by Yang Tingbao, the Shanghai Hongqiao Sanatorium designed by $\mathrm{Xi}$ Fuquan, the Shanghai Hospital designed by Dong Dayou and the Peking University Hospital designed by Zhang Cuan came out one after another.

2) The rise and development of hospices: In 1967, Dr. Saunders, the advocate and founder of hospice care, established St. Christopher's Hospice in Hiddenham, South East London, England, out of lofty kindness and moral emotion, and created the great cause of hospice care. Since the mid-1970s, hospice care institutions (hospices) have been established one after another in the world. So far, there are hospice medical institutions in nearly 70 countries and regions.

The English name of the hospice building is also broken down into the following definitions by relevant experts: Hospitality, Organized care, Symptom control, Psychological support, Individualized care, Communication, and Education.

The United States established the first hospice in 1971. By 1988, there were more than 1,800 hospices in the United States. Canada established the first hospice in 1975. By 1983, it had 116 hospices of different types. At the same time, there are more and more academic researches, academic papers and international conferences related to hospices.

The development history of hospices in Asia is much shorter than that in Europe and the United States. The arrival of an aging society has prompted Japan to become the first country in Asia to carry out researches on hospices. Japan has achieved outstanding results in academic research on hospice care, related facilities management and design, and ethics development. In 1981, the first hospice in Japan was established. This is also the first hospice in Asia.

Since Japan opened up the path to explore hospices, other countries in Asia have also begun to explore related fields with a slow but continuous pace.

\section{The Status Quo of Hospices In CHINA AND ABROAD}

\section{A. The Status Quo of Hospices Abroad}

The author selected three representative buildings from different countries to conduct research on the space design and use of hospices.

1) Norra Vram Sanatorium in Sweden: The Norra Vram sanatorium comes from the reconstruction and expansion of a house at the end of the 19th century. The total area of the sanatorium is approximately 2,500 square meters. The affiliated buildings look like farmhouses in the old days of Sweden. The buildings are connected by internal courtyards. The small garden space gives the treated residents plenty of outdoor time. At the same time, the red bricks of the mansion and the auxiliary buildings with different colors embellish each other, making the sanatorium alive in "Fig. 1".

In the interior of the sanatorium, there are different zones designed for patients with different conditions. There is also a long-term and short-term difference in the same zone to make patients get the best care and maintain relatively good moods. At the same time, under the premise of guaranteeing patients' walking and living safety, the sanatorium sets a large green space or public space as the communication area for patients in different sickrooms. This design enables patients with different personalities to find the most comfortable way of getting along with others in "Fig. 2".

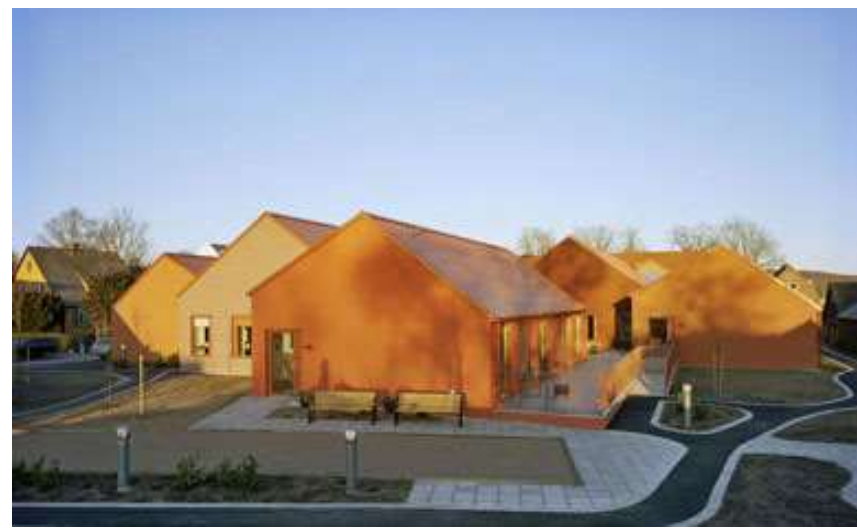

Fig. 1. Outside view of Norra Vram Sanatorium.

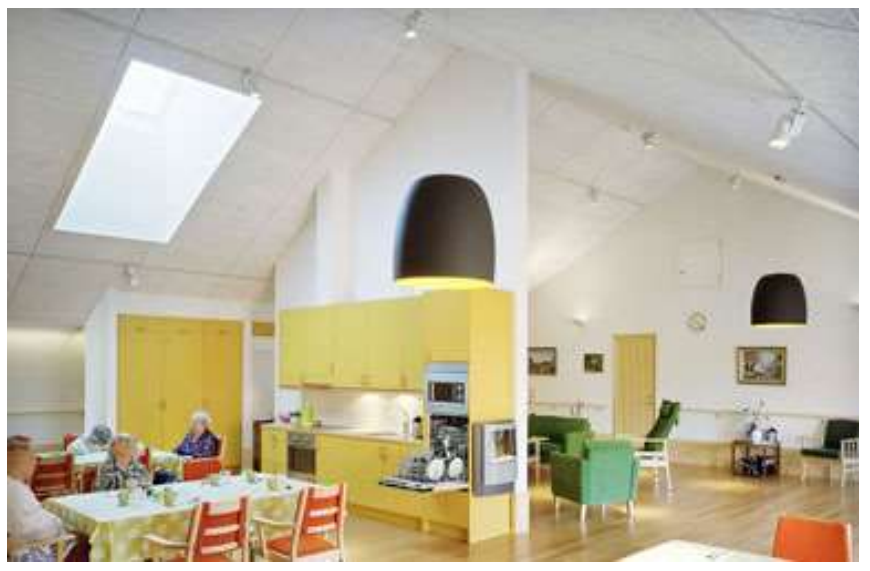

Fig. 2. Internal view of Norra Vram Sanatorium.

2) Hospice søndergaard in Denmark: Hospice Søndergaard is located in Ballerup, on the outskirts of Copenhagen, Denmark in "Fig. 3". It has 14 separate rooms. It is designed to provide dying patients with positive and valuable plans to make them spend the last period of their lives safely and comfortably.

The building is a modern interpretation of traditional farms, with roofed balconies, allowing residents to enjoy the view of the nearby river in "Fig. 4". Inside, it is flanked by two lush gardens, and a green road connects the building with the park and the river. Common areas and employee facilities are located near the entrance so that all houses can protect people's privacy to the greatest extent. 
The internal design of the hospice allows public spaces with large glass windows to connect with different rooms. Good lighting and abundant recreational and sports facilities can effectively improve the patient's physical and psychological conditions in "Fig. 5".

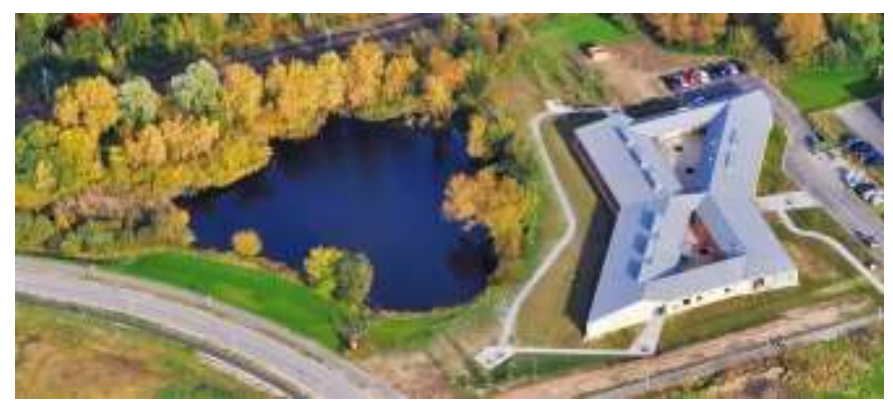

Fig. 3. Aerial view of Hospice Søndergaard.

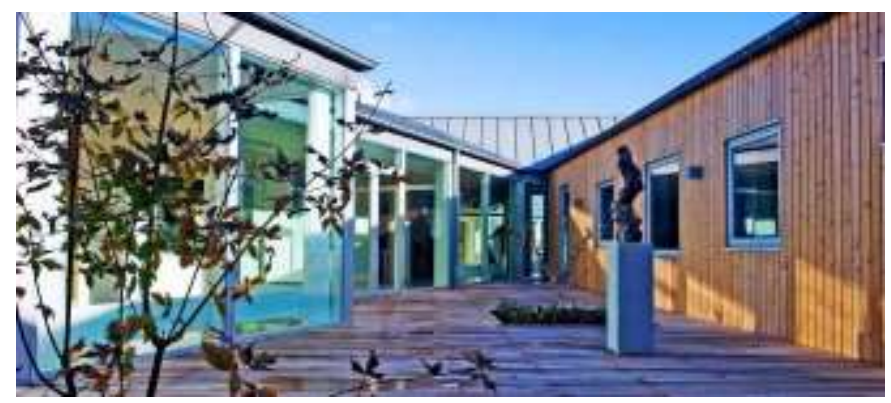

Fig. 4. Exterior corridor of Hospice Søndergaard.

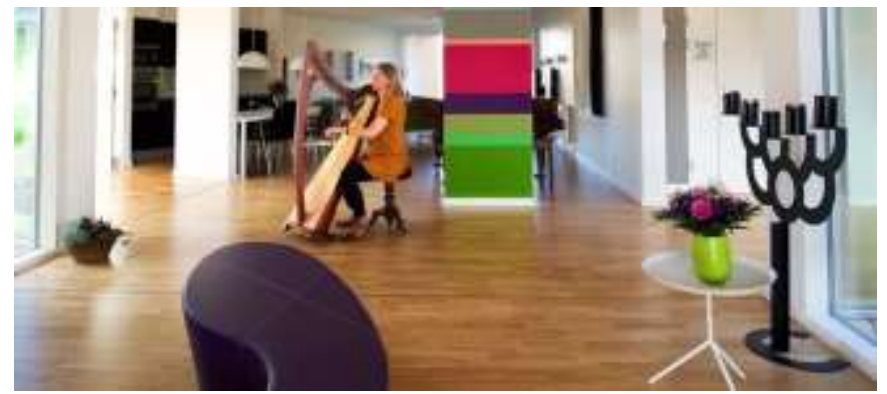

Fig. 5. The Common Area in Hospice Søndergaard.

3) Red cross hospital hospice care center in Morioka, Japan: Japanese architects pay great attention to practicing the concept of green environment. In the design of the Red Cross Hospital Hospice Care Center in Morioka, "green" has become the protagonist, and the building is only a supporting role in this complex. The building hides in the shade of trees and blends in perfectly with the surrounding natural environment. At the same time, the architects designed courtyards and skylights for the hospice care center to introduce sunlight and breeze. Even the roof is not just a simple sloping roof. Skylights have been added to it to allow residents to bathe in natural light at all times and feel the time as the light changes. The design of the wooden terrace has greatly satisfied the resident's quest for fresh outdoor atmosphere in "Fig. 6".

The design of the interior space emphasizes the concept of "communication". Activities such as concerts or game competitions are often organized in the entrance hall to make it a communication place with lively atmosphere. In addition, there are cafeteria seating areas, family activity rooms, and talking corners to allow patients and their families to freely choose the communication place that is suitable for them in "Fig. 7".

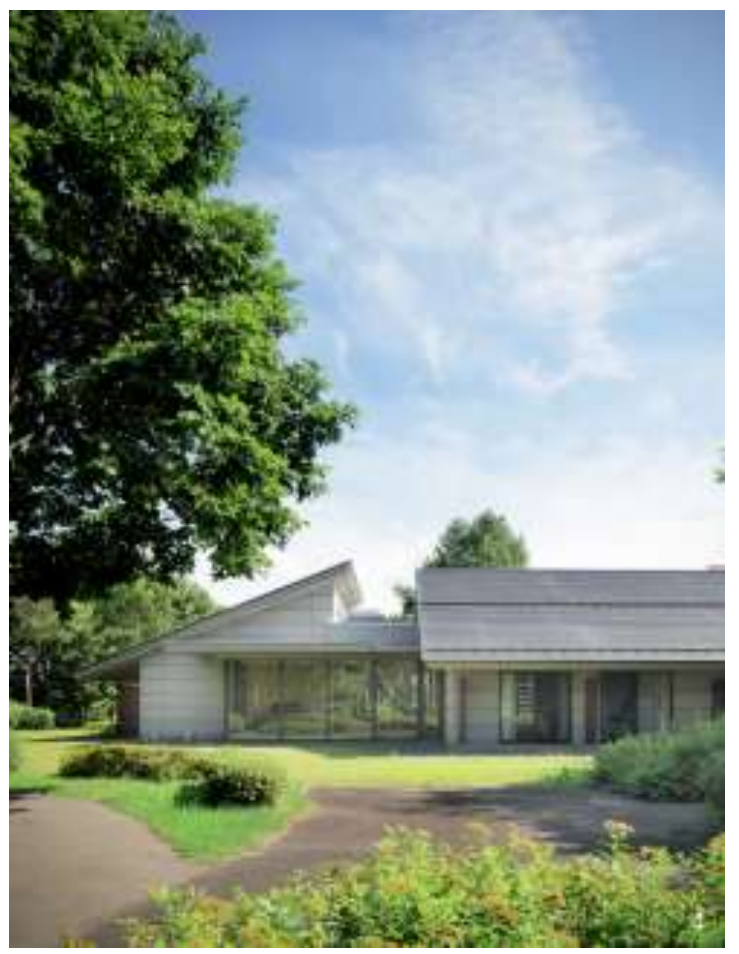

Fig. 6. External View of Morioka Red Cross Hospital.

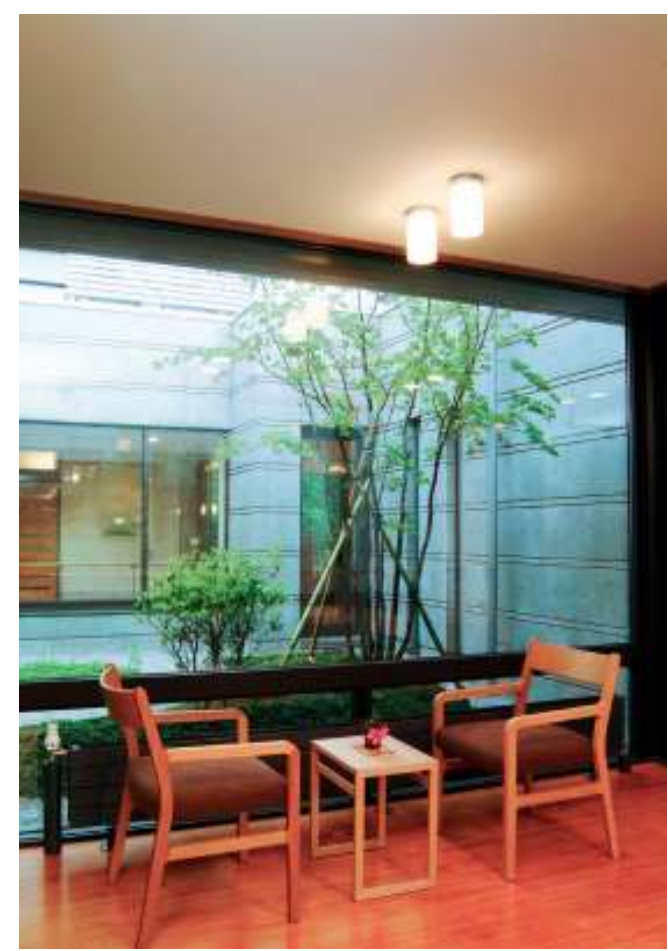

Fig. 7. The dining room in Morioka Red Cross Hospital. 


\section{B. Status of Hospices in China}

According to historical records, there were already specialized retirement sites in China two thousand years ago, but limited by the medical level, additional nursing homes for chronic patients were not provided. It was until in modern times that a specialized hospice was established in Hong Kong.

China's hospices can be divided into three major categories:

- Independent hospices. They have relatively complete medical facilities and professional care workers. The care methods are more professional and standardized. Their architectural design focuses on space arrangement, designing different styles and colors for different needs, which can to the greatest extent make the patient feel comfortable and free.

- The community wards attached to the community medical service center. It is the main mode that has been vigorously developed in China in recent years. Community care has a relatively complete system and plan, but the patient's living place is not as comfortable and free as that of the independent hospices. And the impact of design and color on the patient has not been fully considered.

- The hospice care unit attached to a general hospital. It is mainly based on hospice wards and districts. It is currently the most common hospice care model in China. However, it is not a one-to-one service model. It shares a batch of equipment and space with other departments in the hospital. The space design lacks human touch and does not provide a comfortable communication space for patients and their families.

1) Beijing songtang care hospital: Beijing Songtang Care Hospital is the first hospice in China, which was established in 1987. Songtang Care Hospital not only has the function of hospice care but also can be a nursing home. Therefore, it is not just a simple hospice.

Songtang Hospital has adopted the Chinese architectural style as its main architectural style, but the interior still adopts the design style of general hospitals. The design highlights of Songtang Hospital are the Chinese-style octagonal kiosks and other landscape pieces, which provide the patients and the elderly with space for communication and relaxation.

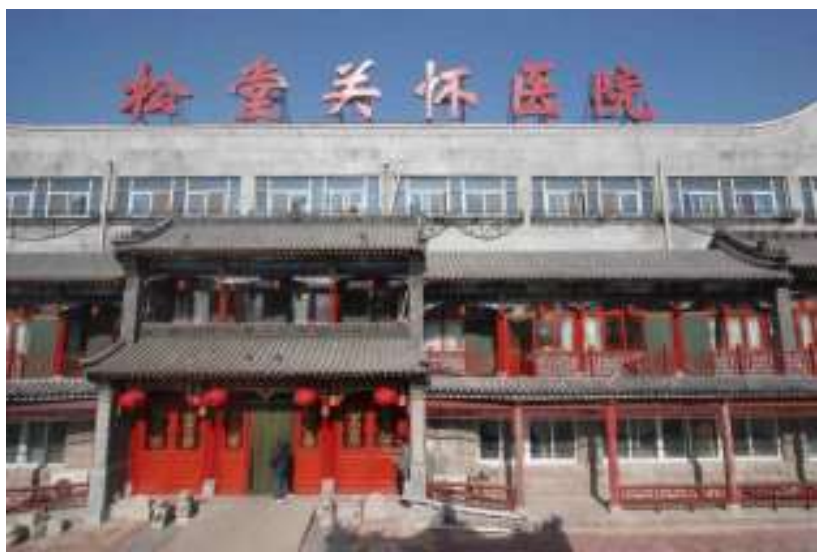

Fig. 8. Front view of Songtang Care Hospital.
2) Hospice wards in peking university shougang hospital: The author once participated in the renovation and design of hospice wards in Peking University Shougang Hospital. As the most popular hospice ward design in China today, the design of the hospice ward in Shougang Hospital has also been put in this article for a more comprehensive and comparative study.

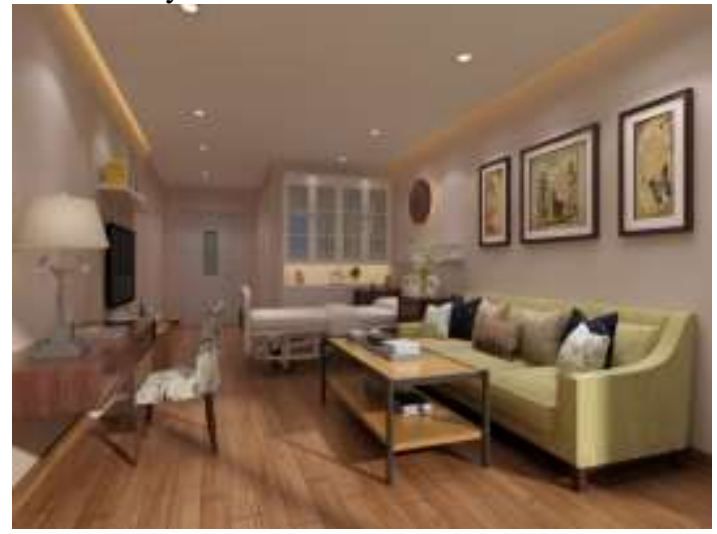

Fig. 9. Internal Rendering of the Hospice Room in Shougang Hospital.

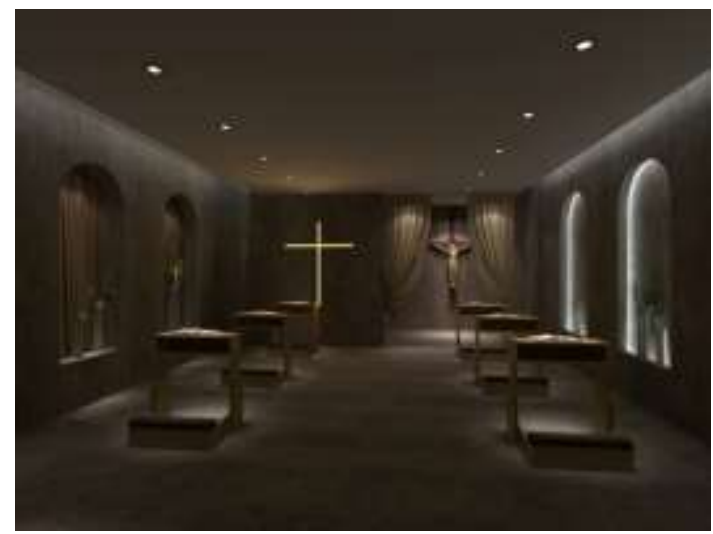

Fig. 10. Rendering of the Prayer Room in the Hospice Room in Shougang Hospital (1).

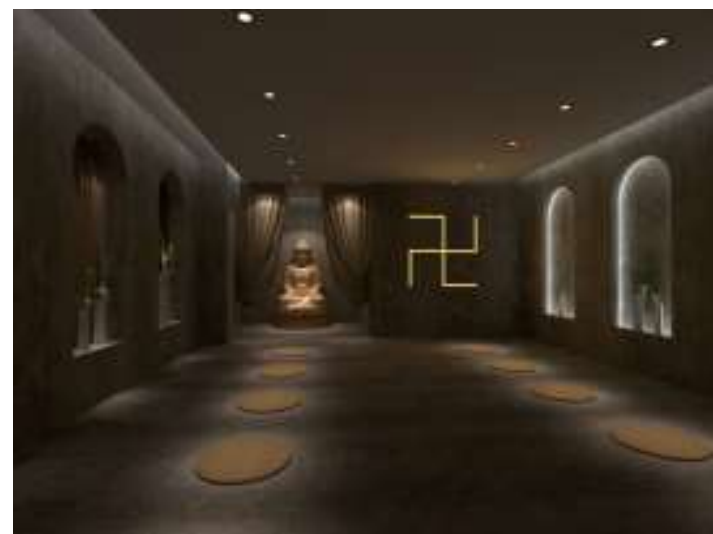

Fig. 11. Rendering of the Prayer Room in the Hospice Room in Shougang Hospital (2).

This hospice ward is not only more humanized and has a home atmosphere in interior design, a religious prayer room is also added to this hospice ward in addition to the commonly 
used functional spaces, so that the patient can not only get good physical care but also have a space to relieve psychological pressure.

\section{STUdy ON THE DESIGN OF HOSPICES}

The intensification of aging society in China and the increase in the incidence of major chronic diseases have led to a significant increase in the demand for hospices, the functional building space. As a civilian building that is not the same as a hospital, a hospice should contain more humanfriendly and practical elements in addition to the necessary medical equipment.

\section{A. The Landscape Design of Hospices}

Unlike hospitals that pursue efficient treatment processes, hospices pursue a more soothing environment. From the perspective of landscape design, a large area of vegetation cover and a large space for outdoor activities are very helpful to enhance the patient's sense of well-being and comfort. In different seasons, it should be ensured that there are ornamental plants in the outdoor landscape. For the patients, there should be not only good scenery but also a small space for communication, such as the Chinese traditional octagonal pavilion or the western common wooden huts.

At the same time, the landscape design of hospices not only refers to the exterior landscape design of the building, but also refers to setting up patios to plant plants inside the building. Landscapes such as waterfalls can also be added to relieve the patient's mood.

\section{B. The Interior Design of Hospices}

1) Functional division and design of indoor space: As the hospice building, hospices should not only have the necessary medical function space, but also have the corresponding space set up after truly considering the patient's feelings. The patient's main living space is focused on the degree of comfort, and the housing area is decorated with natural materials that can relax patient's body and mind, and appropriate lighting areas and sound insulation design are added.

Of course, human sociality determines that humans cannot live without communication. The establishment of public dining rooms, public leisure areas and sports areas at the confluence of rooms in the hospice can meet the patient's needs for communication, and it will not cause too much interference to people who prefer to stay quiet.

From ancient times to the present, no matter in the East or in the West, many people have their own beliefs or spiritual sustenance. In response to this demand, religious prayer sites have also become one of the main elements in the design of the interior space of hospices. We shouldn't ignore the physical and psychological comfort that faith brings to the patient. The design of the prayer space enables the patient to get psychological comfort and relieve their stress.

2) Subsidiary design of hospices and the surrounding space: After satisfying basic space and functional requirements, how to select the right color and lighting is the problem to be considered. In terms of space color, the living space should adopt light and warm colors that can ease the mind and body, the public leisure space can adopt lively and bright colors, and the outdoor painting can use natural colors.

The first consideration in space lighting design is the safety of patients and their families when they are moving around in space. The corners and functional spaces need to adopt bright and soft light, and the rest space should adopt soothing light. The entertainment space should use multiple light to meet different needs of residents.

\section{CONCLUSION}

The dying is the notice that life is coming to an end. However, dying is not equal to passively waiting for death. This stage is also a part of life or even an essential part of life. Taking effective and positive measures to improve the quality of dying also reflects the respect of the whole society for life. The design and development of hospices still needs the extensive participation and efforts of the whole society. The development of hospices is also necessary for today's China.

This paper focuses on the following aspects:

- Introduce and explore the definition of hospice and the purpose and development of hospices.

- Find the important elements in the design and development of hospices by exploring the environment and design of several hospices in China and abroad.

- Deeply explore the elements that should be emphasized or must be provided in the design of hospices, review in terms of landscape, interior, lighting, and color.

Through the research and discussion on hospice care and hospices, the researcher believes that in the face of the current aging population and the increase in the incidence of major chronic diseases, there are still problems to be solved in the development, selection, definition and design of hospices in China. These deficiencies also mean that Chinese society generally lacks attention in this field. How to optimize designs for patients and their families in this field is a question that everyone in the design industry needs to consider. Providing the dying people with the care they want is also, in some ways, providing us with a more effective life guarantee for the future.

\section{REFERENCES}

[1] Marcus C C. Healing gardens in hospitals[J]. Interdisciplinary Design and Research e-Journal, 2007, 1(1): 1-27.

[2] Reiling J G. Creating a culture of patient safety through innovative hospital design[J]. 2005.

[3] Joseph A, Rashid M. The architecture of safety: hospital design[J]. Current opinion in critical care, 2007, 13(6): 714-719.

[4] Wang Shengjie. Research on the development and design strategy of China's hospice medical buildings[D]. Hunan University, 2010. 王圣洁. 我国临终医疗类建筑的发展及其设计策略研究[D]. 湖南大学, 2010 .

[5] Fu Liewu. An Analysis of the Architectural Design of Hospice Centers in the UK- - Taking Trinity Hospice and St. Christopher's Hospice as the Example[J]. Urbanism and Architecture,2014(22):pp.41-43. 付列武. 
英国临终关怀中心建筑设计解析一一以一临终关怀中心和圣里克 斯多弗临终关怀中心为例[J].城市建筑,2014(22):41-43.

[6] Wang Xiaobo, Liu Yao, Zhou Xi. Garden of Houston Hospice[J].Chinese Landscape Architecture,2012,28(05):pp.95-98. 王 晓博,刘尧,周曦.休斯顿临终关怀院花园[J].中国园林,2012,28(05):9598.

[7] Stephen Weidberg, Ben Reeves, Chao Jun. Hospice Care Hospitals in the 21st Century [J]. Urbanism and Architecture, 2008(07):pp.28-30. 斯 蒂芬・魏德勃,本・瑞夫卓,炛军. 21 世纪的临终关怀医院 [J].城市建 筑,2008(07):28-30.

[8] Editorial Office of the Journal, Zhou Ying. The Japanese Pension Buildings[J]. Chinese Hospital Architecture and Equipment, 2016(05):p.26. 本刊编辑部,周颖.日本养老建筑[J].中国医院建筑与装 备,2016(05):26. 